The names of diseases listed here are numbered by intervals of ten, from 10 to 7570 . Are these as useful for geneticists as McKusick's Mendelian Inheritance in Man (MIM)? They are certainly more logical as explanations of the clinical disease as they are largely based on function and gene product. Of course the MIM catalogue is more comprehensive and contains unexplained syndromes and diseases including those that have appeared only once. Nevertheless, the clarity and logic of this volume VI of the International Nomenclature of Diseases commend themselves to clinical geneticists, particularly for those studying or reporting patients with biochemical errors. It is a remarkable achievement to have produced a nomenclature of these metabolic and endocrine disorders that can be used throughout the world, and I eagerly await future volumes.

\section{S BUNDEY}

Molecular Mechanisms and their Clinical Application in Malignancies. Ed D E Bergsagel, T W Mak. (Pp 270; \$49.95.) San Diego: Academic Press. 1991.

This book is the publication of the twelfth annual Bristol-Myers Squibb Symposium on Cancer Research. The book covers the four sections of the two day symposium: the genetic basis for neoplasia, genetic abnormalities in specific tumours, genetic basis of the cellular response to therapy, and application of molecular biology to clinical treatment. The book aims to make available current ideas and knowledge from some of the foremost investigators in cancer research to a wider group of scientists and particularly clinicians. The result is a very varied assortment of molecular and cell biology in and around the cancer field. The wide range of contributors gives the reader an insight into linkage and cloning studies, resistance to anticancer drugs, possible inherited enzymic determinants in lung cancer, functions of interleukin, regulation of transcription, biology of oncogenes, loss of tumour suppressor genes, retinoid and thyroid hormone receptors, and $\mathrm{T}$ cell receptor genes in malignant disease.
The inevitable tendency to report current knowledge leaves the information, already out of date in some chapters, suspended in time without the benefit of history. For instance the cloning of the genes for type 1 neurofibromatosis and adenomatous polyposis coli came too late for publication. Some chapters cater for a limited understanding of the field (molecular genetic analysis of the phakomatoses) whereas others launch straight into jargonese. There are good chapters on retinoblastoma and cachectin in the biology of cells which are clear, concise, and well structured. There is very limited content on clinical application of the knowledge except towards the end of the book (structural design in antitumor compounds). The book may be useful to a wide range of people in or around the cancer field. There could have been a better finished product with more active editing including that of the format which was not consistent. Scientists in the research field are more likely to benefit than clinicians unless they too have an active research interest. The book is unlikely therefore to fulfil one of its primary objectives of keeping clinicians abreast of the current research. Such an aim could only have been achieved by simplifying the data and giving more explanation. This would then have made the finished product less valuable to the researcher.

D G R EVANS

Molecular Genetic Approaches to Neuropsychiatric Diseases. Ed Jurgen Brosius, Robert T Fremeau. (Pp 493; \$69.95.) New York: Academic Press. 1991.

This book sets out to provide series of up to date reviews of the application of molecular genetic techniques to the study of a variety of 'neuropsychiatric diseases'. Part I is concerned with methodology. The first two chapters review recent technological advances in molecular genetics and the third chapter describes the principles of human genetic linkage analysis. Part II contain three chapters on the molecular genetics of metabolic diseases covering mitochondrial diseases, lysosomal storage diseases, and Lesch-Nyhan syndrome. Part III covers the molecular genetics of neuromuscular dis- eases and includes chapters on Duchenne and Becker muscular dystrophy and on myotonic muscular dystrophy. Part IV considers the molecular genetics of neoplastic and viral diseases of nervous tissue and includes chapters on neurofibromatosis types 1 and 2 , retinoblastoma, and viral diseases of the nervous system. Part V contains chapters on Alzheimer's disease and schizophrenia. Part VI is concerned with mental retardation and contains chapters specifically on the fragile $\mathrm{X}$ syndrome and an overview of molecular genetics and mental retardation. The final part is concerned with animal models.

It can be seen from the book's contents that the Editors' concept of 'neuropsychiatric diseases' is a broad one and the book would have perhaps been better entitled 'Molecular genetic approaches to neurological and psychiatric diseases'. In general the standard of the chapters is extremely high and the Editors have managed to recruit a distinguished collection of 'big name' auth ors. The book suffers from two of the problems that beset multiauthor texts in this field. First, there is some repetition of basic concepts and also in the coverage of specific diseases, for example, both Tay-Sachs disease and fragile $\mathrm{X}$ syndrome have chapters dedicated to them yet are also covered in some detail in the chapter on mental retardation. No doubt one of the drawbacks of having distinguished authors is that it makes editorial pruning more difficult! Second, a number of the chapters have already been overtaken by recent advances, for example, Alzheimer's disease, fragile $\mathrm{X}$ syndrome, myotonic dystrophy, and neurofibromatosis 1. The focus of the book is very much on molecular biological techniques and clearly shows how these have led to remarkable advances in understanding a wide range of diseases affecting the nervous system. In their preface, the editors claim that this book is "intended to benefit a broad audience ranging from graduate students to established investigators, and from clinical neurologists and psychiatrists to molecular biologists interested in neuropsychiatric diseases". They also hope that it will "convey the sense of excitement and promise that accompanies on-going research". In my opinion it fulfils these claims admirably ar:d I strongly recommend it.

M OWEN 